\title{
Is it adaptive to disengage from demands of social change? Adjustment to developmental barriers in opportunity-deprived regions
}

\author{
Martin J. Tomasik • Rainer K. Silbereisen • \\ Jutta Heckhausen
}

Published online: 13 August 2010

(C) The Author(s) 2010. This article is published with open access at Springerlink.com

\begin{abstract}
This paper investigates how individuals deal with demands of social and economic change in the domains of work and family when opportunities for their mastery are unfavorable. Theoretical considerations and empirical research suggest that with unattainable goals and unmanageable demands motivational disengagement and self-protective cognitions bring about superior outcomes than continued goal striving. Building on research on developmental deadlines, this paper introduces the concept of developmental barriers to address socioeconomic conditions of severely constrained opportunities in certain geographical regions. Mixed-effects methods were used to model cross-level interactions between individual-level compensatory secondary control and regional-level opportunity structures in terms of social indicators for the economic prosperity and family friendliness. Results showed that disengagement was positively associated with general life satisfaction in regions that were economically devastated and has less than average services for families. In regions that were economically well off and familyfriendly, the association was negative. Similar results were found for self-protection concerning domain-specific satisfaction with life. These findings suggest that
\end{abstract}

M. J. Tomasik ( $\square)$

Center for Applied Developmental Science, Friedrich Schiller

University, Am Steiger 3/1, 07747 Jena, Germany

e-mail: s4toma@uni-jena.de

R. K. Silbereisen

Department of Developmental Psychology

and Center for Applied Developmental Science,

Friedrich Schiller University, Jena, Germany

J. Heckhausen

School of Social Ecology, University of California at Irvine,

Irvine, CA, USA compensatory secondary control can be an adaptive way of mastering a demand when primary control is not possible.

Keywords Developmental regulation - Primary and secondary control $\cdot$ Life-span theory of control . Disengagement - Subjective well-being - Social change . Globalization · Social ecology · Context · Opportunity structures

\section{Introduction}

Life in a globalized world is shaped by institutional deregulation, accelerated social and technological change, an increasing plurality of norms and values, and a new individualism which confronts men and women with great advantages but also with new risks of failure to achieve their personal goals and strivings (Elliott and Lemert 2006). The rapid changes in the social fabric and the growing structural uncertainty at the societal level (Hofäcker et al. 2010) provide less organizational structure on the individual life course (Brückner and Mayer 2005) and produce developmental ecologies that require more and not less individual agency, intentionality, and self-regulative efforts from the individual (Brandtstädter 2010; Heckhausen 1999; Heckhausen et al. 2010). Psychological research on social change suggest that the primary link between the macro level of social change and the micro level of individual behavior can be conceived in terms of individually perceived demands that disturb habits, interrupt routines, and index a new state of affairs relative to what the individual was accustomed to (Pinquart and Silbereisen 2004; Tomasik and Silbereisen 2009). Take as a case in point the situation in Eastern Germany before and after political unification in 1990. The labor market, which was 
characterized by high security under the communist command economy rule, was devastated in the course of market liberalization as companies were no longer able to stand the competition in product quality and productivity. The following increase in precarious types of employment on the labor market produced economic hardships and disturbed routine career planning. Over and above the increased uncertainty, individuals were confronted with acculturative demands of acquiring new qualifications and learning new behaviors that are required under the new political system. Individuals who were challenged by many of such demands at the same time were at risk to overtax their personal and social resources and needed to find adaptive responses to deal with them adequately (Pinquart and Silbereisen 2004).

In this paper, we want to demonstrate empirically that there are situations where an adequate response to such and similar demands of social change requires not overcoming them by putting in more effort but rather by quitting commitment and disengaging from their mastery. The crucial factor we want to investigate is the level of opportunities for goal striving provided by the social ecology. The level of opportunities provided should determine whether engagement with cumulated demands or disengagement from them is more adaptive. Such ecologies and the inherent opportunities have changed due to globalization and political transitions of the last few decades, and at the outset of this paper we want to briefly illustrate how historical change in opportunities influenced individual responses to social change. Subsequently, we want to define the different responses more systematically and provide both theoretical and empirical evidence that it is generally more adaptive to disengage when opportunities are low. In the hypotheses to follow we address the beneficial function of disengagement by investigating individual's responses to demands of social change across different geographical regions with low versus high opportunities for goal striving.

\section{Changing opportunity structures and individual responses}

Individual agency is bounded by the scope of action opportunities provided by the social ecology (Heckhausen 1999) and these may either increase or decrease in the course of social change, such as the transition from communisms in parts of Europe in the 1990s. Let us consider the case of increasing opportunities first. If there are plenty of opportunities (e.g., expansive labor market due to economic growth), individuals seize the occasion to capitalize on effort and persistence and, for instance, tend to expedite life-course transitions such as the entry into the labor market (Bynner 2001). There are also studies demonstrating that under such circumstances human agency factors become important predictors for developmental outcomes (e.g., Shanahan et al. 1997). A case in point is a study investigating occupational success in Estonia. The early stage of the country's transition from communism was characterized by weak institutions and a highly deregulated labor market going hand in hand with increasing economic prosperity. During this time, human agency factors such as knowledge and abilities together with persistent orientation towards career improvement predicted more income, higher social status and upward mobility (Titma and Tuma 2005), and a better position in the workforce (Titma and Trapido 2002).

The scenario is quite different if action opportunities become restricted. There is some evidence that rapid social change in combination with decreasing opportunities for individual action resulted in postponed life-course transitions (Hofäcker et al. 2010; Schoon 2007). Deferment particularly applied to those transitions which were deinstitutionalized in the course of social or political transformation and thus required more individual agency (Silbereisen and Wiesner 2000) and to those individuals who were personally affected by strains related to social change such as spells of unemployment in the first years after German unification (Reitzle and Silbereisen 2000) or high barriers to enter the regular labor market (Hofäcker et al. 2010). The postponement of life-course transitions may be considered a case in point for an adaptive reaction to decreasing opportunities. Other reactions observed were the formation of more flexible forms of intimate relationships that do not require making long-term commitments or the shift from blocked developmental pathways into those with more favorable opportunities. An example for the latter is that young people tend to stay longer in the educational system allowing them both to avoid the risk of unemployment and at the same time to improve their qualification for the labor market (Schoon 2007).

All these adaptive strategies to restricted opportunities have in common that they comprise an at least temporary disengagement from developmental goals that are blocked and a flexible adjustment of aspirations towards goals with more promising opportunity structures. The examples demonstrate that there are situations where giving up can turn out more beneficial than staying committed to something which is hardly attainable. In other words, the adaptive value of commitment and disengagement cannot be defined out of itself (Heckhausen et al. 2010). Rather, it is a function of those opportunities and constraints that are linked with the attainment probability of the respective goals and strivings. This is exactly what contemporary notions of developmental regulation suggest as crucial under the current social conditions characterized by 
institutional deregulation and individualism. Brandtstädter (2010), for instance, advocates that positive development does not only hinge on tenacity in pursuing goals but also, and today even more than ever, on sufficient flexibility to adjust them to contextual change. In their dual-process theory of developmental regulation Brandtstädter and colleagues emphasize the importance of accommodating goals to realities and changes in opportunities for maintaining a stable and positive self (Brandtstädter and Renner 1992; Brandtstädter and Rothermund 2002; see also Poulin et al. 2005). The life-span theory of control takes a different stance in that the ultimate criterion for adaptive development is not based on self-consistency but instead on the optimization of primary control striving (i.e., having an active influence one's environment and one's developmental future; Heckhausen and Schulz 1999; Heckhausen et al. 2010; Schulz and Heckhausen 1999). As a consequence the life-span theory of control proposes more generally that disengagement from unattainable goals is adaptive because it preserves resources that could be invested in more feasible goal pursuits (Heckhausen and Schulz 1995; Heckhausen et al. 2010; Wrosch et al. 2003). We want to show that this general proposition applies to demands that derive from contemporary social change (e.g., uncertainty concerning one's occupational career) and that the key to the question whether disengagement is adaptive or not lies in identifying the degree of constraints in the regional social ecology. Specific empirical indicators of opportunity structures are used (e.g., unemployment rate or dropout rate from high schools). The present research combines the issue of individual adaptation to social change with prominent conceptions of developmental regulation in terms of primary and secondary control striving across the life span.

\section{Propositions of the life-span theory of control}

According to the life-span theory of control (Heckhausen 1999; Heckhausen and Schulz 1995; Heckhausen et al. 2010 successful development depends on the individual's ability to carefully adjust goal engagement and goal disengagement to the opportunities and constraints provided by the social ecology in order to maximize one's long-term capacity for control. Goal engagement and disengagement are defined in terms of different control strategies individuals may exert. These were categorized according to a taxonomy originally proposed by Heckhausen and Schulz (1993) and later integrated into the life-span theory of control by the authors (see comprehensive review in Heckhausen et al. 2010).

Individuals may use selective primary control and invest personal resources such as ability, time, and effort or to fight difficulties that arise during goal striving. Learning a foreign language in an increasingly internationalized labor market is a case in point for this type of control. Selective primary control is supported by selective secondary control which is supposed to keep up motivational commitment through the enhanced anticipation of positive consequences or through an enhanced appraisal of one's own capacity for control. If personal resources do not suffice, compensatory primary control can be activated. This type of control striving comprises seeking social support, breaking new ground, or looking for detours and alternative solutions. Whereas the former three types of control represent goal engagement, the function of compensatory secondary control is to protect the individual from the negative effects of failure to do so. The individual disengages from the futile goal and thus saves resources that would otherwise be wasted. Individuals also respond to low controllability situations by protecting their self-esteem, for instance by comparing to others who are worse off or blaming the loss of control to external circumstances.

The life-span theory of control suggests that the adaptive value of engagement and disengagement is fundamentally determined by the opportunities and constraints for primary control striving provided by the social ecology (Heckhausen 1999). If the ecology provides sufficient opportunities, engagement (i.e., selective primary, selective secondary, and compensatory primary control) is likely to pay off in terms of success and allows individuals to maintain or even expand their capacity for primary control. Disengagement (i.e. compensatory secondary control) is not adequate simply because it does not allow an individual to make use of his or her developmental potential. The opposite is true if the ecology does not offer sufficient opportunities to master the respective demands. Under such circumstances, individuals who stay engaged and motivationally committed expose themselves to repeated experiences of failure and waste resources. Strategies of self-protection and disengagement are more adaptive and allow individuals to switch to more promising goals and thus to maintain their capacity for primary control.

There is quite a lot of empirical evidence for the adaptive value of compensatory secondary control under constrained opportunities (Heckhausen et al. 2010), although no research has yet focused on constraints as a consequence of globalization and political transformation. Wrosch et al. (2003), for instance, reported studies that examined the associations between goal disengagement and subjective well-being in students who should imagine themselves in different situations where previous goals became unattainable and in parents of children with cancer. Goal disengagement explained significant proportions of variance in indicators of well-being. Other studies investigated coping with uncontrollable demands during 
extreme life situations such as caring for handicapped children (King et al. 2000; Tunali and Power 1993) or terminally ill patients (Moskowitz et al. 1996) and coping with uncontrollable memory deficits (Williamson and Schulz 1993) or the death of a loved one (Mattlin et al. 1990). Although these studies were thematically and conceptually quite different, all allow the same conclusion. Even extreme stress does not need to result in lower subjective well-being and eventually may be turned into a growth experience if individuals manage to disengage from unattainable goals, aspirations, or ideals and if they are able to protect their motivational and emotional capacities. Staying committed to no longer appropriate goals, on the other hand, seems to obstruct the way to alternative cognitions and actions from which individuals are likely to derive emotional well-being and satisfaction.

Further evidence for the suggested adaptiveness of compensatory secondary control comes from research on developmental deadlines. A deadline is associated with age and implies diminishing opportunities for the attainment of a developmental task which then requires a shift from engagement to disengagement (Heckhausen 1999). As a sample case for a developmental deadline, Heckhausen et al. (2001) investigated the running down of the "biological clock" for childbearing. The authors found for women before the menopause that more selective primary control was associated with less depressive symptoms whereas for women after the menopause this association was positive. Similarly, Wrosch and Heckhausen (1999) studied the less explicit deadline for finding a romantic partner The authors found that in young adults, compensatory secondary control was negatively correlated with change in positive affect whereas in older adults, the association was positive.

\section{The concept of developmental barriers}

To specify the general condition when disengagement becomes beneficial, we want to introduce the concept of developmental barriers. It builds on the previously cited research on developmental deadlines (Heckhausen 1999; Heckhausen et al. 2001; Wrosch and Heckhausen 1999) and characterizes features in the social ecology that limit the effectiveness for primary control with respect to developmental tasks. The concept of barriers thus generalizes the concept of deadlines beyond its temporal dimension (see also Heckhausen et al. 2001, Footnote 1) and there are two criteria constitutive for its definition. First, developmental barriers are characterized by objectively low opportunities for primary control. In other words, increasing effort vis-àvis a developmental barrier is ineffective or at least very inefficient. A case in point is a high unemployment rate which makes it difficult to find a job and to secure a career. Causes for a developmental barrier can usually be found in the social ecology and individuals do not necessarily have to be aware about them. What is more important, however, is that they experience its consequences in terms of low attainment probabilities which finally manifest in frequent failure. Second, developmental barriers strictly relate to long-term processes of developmental goal attainment (e.g., building of an occupational career or parenthood) which are situated on a higher level in the individual's goal hierarchy and posses a higher centrality for the individual as compared to everyday goals and projects (Carver and Scheier 1998). Developmental goals are characterized by long-term investment of effort and commitment, high relevance for the self, usually a complex social embedding, and at least implicit normative value sets. Minor goals and everyday routine actions are more transient, have a lower level of individual involvement and fewer long-term consequences for own development which would require a theoretical framework other than the life-span theory of control to study them adequately.

In order to compare social ecologies with varying developmental barriers in this paper, we want to compare regions that provide different opportunities and constraints for the mastery of developmental tasks including career development and family building. This approach makes use of the fact that political-administrative regions within a country increasingly differ in terms of their industrial structures, income, and opportunities on the labor market. These differences result from changes in regional economic involvement and changes in terms-of-trade in the course of globalization and political transition (Silva and Leichenko 2004). We can thus compare regions that profited from social and political change through the integration into global production chains and the establishment of new industrial and scientific clusters with those that were economically devastated due to closures, relocations, or mergers of companies facing increasing global competition. Inequality between regions, though, is not only limited to economic structures but also seems to translate into parameters that affect individual decisions such as fertility and child rearing (Hank 2002). The local opportunity structures can thus be considered an important factor which determines the effectiveness of primary control striving for both work and family life. Investing time and effort in order to advance one's career or to find a job, for instance, only pays off if the local economy provides opportunities to do so. Otherwise, primary control striving is likely to result in failure. Comparing different regions thus offers an opportunity to test the proposition that engagement and disengagement are linked with different outcomes as a function of varying opportunities and constraints in the social ecology. 


\section{Hypotheses}

Building on the theoretical framework of the life-span theory of control and the empirical evidence cited, the central hypothesis of this paper was that individuals who face a developmental barrier in their home region will be better off in terms of subjective well-being if they try to handle the unattainable demands in a compensatory secondary mode. In other words, strategies of self-protection or even disengagement from unattainable demands were regarded as a necessary condition for subjective well-being if the social ecology does not provide sufficient opportunities for primary control. To test this hypothesis, compensatory secondary control strategies (i.e., goal disengagement, self-protection) were linked with data on regional opportunity structures and concurrent measures of subjective well-being.

This hypothesis was tested for both, the work and the family domain. The two life domains were selected because of their normative significance in the life course and because the socially induced changes in these domains are of special public and scientific interest. Furthermore, we also hypothesized transfer effects between the two domains. Research on the negative impact of unemployment and workplace insecurity on family life, for instance, has demonstrated that the domains of work and family are closely intertwined with each other (e.g., Larson et al. 1994).

\section{Method}

\section{Procedure}

The sample analyzed is part of the Jena Study on Social Change and Human Development. Respondents were drawn in equal shares from four federal German states. These comprised two economically wealthier states (Thuringia and Baden-Wurttemberg) and two economically poorer regions (Mecklenburg-Western Pomerania and Schleswig-Holstein). An almost identical number of inhabitants from these states were interviewed. Each federal state was split further into smaller regional units (administrative districts). Mecklenburg-West Pomerania was divided into 18 target areas, Thuringia into 23, Schleswig-Holstein into 15, and Baden-Wurttemberg into 21. Within each target area sampling points from which to start random route sampling were selected from the ADM register which is representative for the German household population aged 14 and more years. The ADM is a sampling technique with three levels of selection (cf. von der Heyde and Loeffler 1993). First, sampling points were randomly selected from all constituencies in Germany from which, second, households within the target areas were identified by random route. Within the households, third, appropriate persons are selected by a specified procedure. The selection of persons was stratified with regard to age, gender, educational status, and community size. The assessments were conducted as standardized face-to-face interviews by a professional survey institute and lasted about $60-90 \mathrm{~min}$. No compensation was paid to the participants.

\section{Measures}

\section{Demands of social change}

The concept of demands was introduced by Pinquart and Silbereisen (2004) to describe how social change affects the individual. It can be conceived as the translation of macro-level phenomena such as globalization into the proximal developmental contexts of individuals such as work or family life. In these developmental contexts, demands produce uncertainty, index a new state of affairs, and require more than routine action to overcome them (Tomasik and Silbereisen 2009). Six of such demands were assessed for the domain of work and six for the domain of family. Examples of items for the assessment of demands are "When considering the past 5 years it has become more difficult for me to plan my career" or "When considering the past 5 years it is now more likely that my partner could leave me". Note that the participants were asked to rate their endorsement of the statements, on a scale from 1 (does not apply at all) through 7 (fully applies). Further details on this measure are provided by Tomasik and Silbereisen (2009). Based on the twelve items, we computed a composite index by counting all demands that were highly endorsed as indicated by a scale value of 6 or 7 . The formation of such an index was made against the backdrop of earlier research that proved the cumulation of stressors as the actual risk factor for psychosocial adaptation (e.g., Sameroff 2000). Results discussed elsewhere showed that whereas the endorsement of single demands was quite high, a cumulation of high demands was rather rare (see Tomasik and Silbereisen 2009).

\section{Compensatory secondary control}

A newly developed scale was used to assess control strategies for mastering demands of social change in each of the life domains (for details see Tomasik 2008). In the original interview we assessed control strategies concerning demands in the domains of work, family, and public life. This paper focuses on work and family only, although the measurement model necessarily comprises all three life domains in order to reliably estimate the method effects in the latent measurement models that were set up independently for each 
control strategy. In order to account for the multidomain structure of the assessment, a latent trait-state-model was preferred (Pohl et al. 2008). The state component represented the domain-specific variance of the respective control strategy within the three domains of life. The repeated measurement of the single items was accounted for by M-1 method factors according.

The scales were assessed immediately after the assessment of the respective demands and by paper-pencil in the otherwise oral interview. Participants were asked to rate the six demands related to work and then to indicate how they dealt with them in terms of control striving. Subsequently the procedure was repeated for the six demands related to family life. Participants were asked to rate their endorsement for each control item on a scale ranging from 1 (does not apply at all) to 7 (fully applies). Compensatory secondary control was assessed with two independent scales. The first scale focused on the function of compensatory secondary control to protect motivational and emotional resources of the individual in case of (temporary or finally) failure. The scale measuring this self-protective compensatory secondary control comprised the items "If I can't handle these changes then I search for grounds not to have to give myself the blame", "If I can't find a solution then I search for explanations which enable me to justify myself in my own mind", and "If I don't manage to find a good solution whatsoever then I search for plausible reasons why I am not at fault". The measurement model fitted the data very well $\left(\chi^{2}(13)=18.75, p=.13 ; \quad\right.$ RMSEA $=.012$; standardized RMR $=.009 ; \mathrm{GFI}=1.00)$.

If the mastery of demands is no longer feasible at all strategies of compensatory secondary control that ease disengagement become important. The items used to assess this strategy were "If I can't find a solution then I put the problem to the back of my mind", "If nothing works out then I no longer take the whole thing seriously", and "If I can't handle these changes at all then I don't concern myself with them any longer". This model fit the data very well, both in terms of the discrepancy measure $\left(\chi^{2}(13)=17.48\right.$, $p=.18$ ) and other fit indices (RMSEA $=.011$; standardized $\mathrm{RMR}=.011 ; \mathrm{GFI}=1.00)$.

\section{Opportunity structures}

Indicators for the opportunity structures in the domain of work and family were derived from aggregate data at the level of administrative counties ("Landkreise"). In the federal system of Germany, counties are the smallest units of political self-administration with a scope for political decision making. The within variance of legislation concerning labor market or social policies is consequently very low. Furthermore, counties represent the smallest units for which social indicators are reliable, comparable, and easily accessible. With an average size of only $1,200 \mathrm{~km}^{2}$ (460 sq mi) they comprise an area which is easily accessible with current means of transportation and thus can really be considered the broader context of development relevant for work and family life.

In order to obtain measures that are valid for individuals in a wide range of life circumstances, a multidimensional approach was necessary. For the domain of work, four indicators were used including: (1) the unemployment rate relative to the number of employed, (2) the overall labor force participation of 15-65 year olds, (3) the proportion of welfare recipients in the population, and (4) the proportion of long-term unemployed in all unemployed. The choice of these indicators was based on a study on the regional prosperity in Germany (Institut der deutschen Wirtschaft 2007). All data referred to the years 2005 or 2006, the unemployment rate was computed as the monthly average for October 2005.

For the domain of family a multi-faceted index according to Bucksteeg et al. (2006) was composed reflecting the aspects of: (1) demography, (2) education and labor market, and (3) safety and wealth. "Demography" was represented by the proportion of children and adolescents under 18 years on the total population in 2002, the total fertility rate in 2000 , and the net migration ratio of the 18-50 years old in 2000. "Education and labor market" was composed of the proportion of high school dropouts in 2001, the average unemployment rate in 2003, the density of open apprenticeship positions in 2001, and the proportion of unemployed adolescents and young adults (under 25 years) on all adolescents and young adults between 15 and 25 years of age in 2002. The factor "safety and wealth" was composed of the number of assaults and burglaries in 2003, the proportion of injured children (under 15 years) in road traffic accidents on all children in that age group, and the proportion of children and adolescents dependent on welfare payments in 2002.

Every single indicator was z-standardized and two indices for regional opportunity structures were computed by summing up the respective indicators. Each indicator was thus incorporated with an equal weight into the respective index. Then the two indices were again $z$-standardized so that the mean was $\mathrm{M}=.00 \quad(\mathrm{SD}=1.00)$ across all subjects.

\section{Satisfaction with life}

Satisfaction with life was chosen as an indicator for subjective well-being. Satisfaction with life is one important aspect of subjective well-being and represents its cognitive and evaluative dimension (Diener 1984). Life satisfaction is responsive to current situational factors such as critical life events, for instance (Stallings et al. 1997). There is also 
some support that life satisfaction reflects current societal living conditions as well as the ability to change them to the better in terms of access to power (Tesch-Römer et al. 2008). It thus was a promising and interesting variable for the current investigation.

Satisfaction with life was measured with regard to life in general as well as with regard to work and family situation. Respondents were asked "How satisfied are you at present with your life altogether", "How satisfied are you with life in your family?", and "How satisfied are you with your work, education or training?". They could answer on a scale ranging from 1 ("very dissatisfied") to 7 ("very satisfied"). Single item measures of life satisfaction are quite common and proved sufficiently reliable and valid measures of the underlying construct (Campbell et al. 1976).

\section{Initial sample}

The initial sample comprised $N=2,863$ adolescents and adults aged 15-43 years, $N=698$ (24.4\%) from Mecklenburg-West Pomerania, $N=709$ (24.8\%) from Thuringia, $N=705(24.6 \%)$ from Schleswig-Holstein, and $N=751(26.2 \%)$ from Baden-Wurttemberg. The equal distribution of participants across the four federal states was intended by design. One half of the sample (52.6\%) lived in communities with less than 20,000 inhabitants, $28.9 \%$ lived in communities with $20,000-100,000$ inhabitants, and $18.5 \%$ lived in communities with more than 100,000 inhabitants. This is quite representative for the federal states studied but as compared with the entire Federal Republic of Germany urban areas were underrepresented. The mean age of the participants was $M=31.23$ $(\mathrm{SD}=8.67)$ years and $45.9 \%$ were male. About one half of the sample (52.3\%) has graduated from or was currently visiting a high school. One quarter $(23.1 \%)$ was in or has attended compulsory school and another quarter $(24.6 \%)$ in college-bound education. About one half of the sample (54.1\%) was not married, which does not mean that all those subjects were outside any personal relationship. Another $37.9 \%$ of the sample were married, $7.4 \%$ were divorced, and only $0.6 \%$ were widowed. A little more then a half of the sample (52.3\%) reported having own children. If participants had any kids, their mean number was $M=1.75(\mathrm{SD}=.84)$. Again about a half of the sample $(51.5 \%)$ was in gainful employment, the other half $(48.4 \%)$ was not. Four subjects $(0.1 \%)$ refused to report their employment status. If the participants were employed then they worked in the average $M=36.10 \quad(\mathrm{SD}=20.34$ ) hours per week. If participants were not in gainful employment, they were either still in education $(42.7 \%)$, unemployed (33.2\%), homemakers $(13.7 \%)$, on maternity leave $(6.4 \%)$ or not employed for other reasons $(4.0 \%)$.
Study sample

For individuals who experience few or even no demands the hypotheses formulated here are of little relevance. More specifically, testing the hypothesis for the entire sample representing the entire range of demand load could make the compensatory secondary control measures meaningless for a substantial proportion of the sample. This is so because the wording of the respective items becomes semantically meaningless if there is little to cope with as in the case of low demands load. We therefore needed to exclude all participants who experienced few or no demands. Furthermore, one can also expect that selfprotection and disengagement (as all other control strategies) become more momentous with an increasing load of demands the individual is confronted with-although there is probably no simple linear relationship here as the negative effects of any adversities usually set in with their sufficient accumulation and then increase exponentially (see Sameroff 2000). Only with a very high load of demands, the urgency of applying compensatory secondary control strategies under unfavorable opportunity structures is particularly pronounced. This would call for studying subjects with a very high load of demands only. Beyond the issue of internal validity, though, one also needs to consider the aspect of statistical power. Since interaction hypotheses were involved, the nominal effect sizes were expected to be small (see McClelland and Judd 1993) so that the sample size investigated needed to be sufficiently large. Therefore, a compromise needed to be found.

Based on preceding power analyses, the cutoff value for defining the study sample was set to six highly endorsed demands out of twelve possible and subjects were excluded if their six high demands were in one life domain only. This cutoff criterion resulted in an effective sample size of $n_{\text {eff }}=806$ subjects which is about $28 \%$ of the initial sample. For this sample size, the power to detect small effects $\left(f^{2}=.02\right)$ at an alpha error level of $\alpha=.05$ is (1$\beta)=.98$, which is very high. Thus, the selected sample size seems to be a reasonable compromise between the need for the selection of highly demanded individuals and substantial statistical power. Table 1 provides the means and standard deviations of all variables used in the models for the initial and the study sample. Tables 2 and 3 provide the correlations of all variables based on the study sample.

\section{Results}

All calculations were conducted with the open source statistical programming language R (R Development Core Team 2006) which is an open-source equivalent to S-PLUS. Full information maximum likelihood has been used as the 
Table 1 Means and standard deviations of all individual variables in the initial and the study sample

\begin{tabular}{lll}
\hline & $\begin{array}{l}\text { Initial sample } \\
N=2,863(100 \%)\end{array}$ & $\begin{array}{l}\text { Study sample } \\
N=806(28.2 \%)\end{array}$ \\
\hline Self-protection work & $3.27(1.40)$ & $3.42(1.58)$ \\
Self-protection family & $3.22(1.49)$ & $3.38(1.68)$ \\
Disengagement work & $3.02(1.47)$ & $2.98(1.64)$ \\
Disengagement family & $3.01(1.53)$ & $2.98(1.68)$ \\
General life-satisfaction & $5.04(1.37)$ & $4.51(1.56)$ \\
Satisfaction with work & $4.80(1.81)$ & $4.12(2.14)$ \\
Satisfaction with family & $5.58(1.46)$ & $5.48(1.64)$ \\
\hline
\end{tabular}

Table 2 Correlation coefficients between all measures in the domain of work

\begin{tabular}{lrrrrrr}
\hline & 1 & 2 & 3 & 4 & 5 & 6 \\
\hline 1. Demands work & & & & & & \\
2. Self-protection work & .06 & & & & & \\
3. Disengagement work & .04 & .52 & & & & \\
4. General life-satisfaction & -.14 & .00 & .03 & & & \\
5. Satisfaction with work & -.20 & .00 & -.05 & .55 & & \\
6. Satisfaction with family & -.02 & -.06 & -.08 & .40 & .23 & \\
7. Opportunities work & -.09 & -.06 & -.01 & .04 & .00 & -.15 \\
\hline
\end{tabular}

Table 3 Correlation coefficients between all measures in the domain of family

\begin{tabular}{lrrrrrr}
\hline & 1 & 2 & 3 & 4 & 5 & 6 \\
\hline 1. Demands family & & & & & & \\
2. Self-protection family & .08 & & & & & \\
3. Disengagement family & .07 & .55 & & & & \\
4. General life-satisfaction & .00 & .01 & -.03 & & & \\
5. Satisfaction with work & .09 & .02 & -.06 & .55 & & \\
6. Satisfaction with family & -.13 & -.06 & -.07 & .40 & .23 & \\
7. Opportunities family & .01 & -.01 & -.03 & .02 & .05 & -.09 \\
\hline
\end{tabular}

optimization algorithm for fitting the model parameters to the data. All variables were centered at the grand mean and standardized prior to the computations. In order to account for the grouped structure of the data, a set of mixed-effects models was computed using the nlme-library by Pinheiro et al. (2006). For each combination of response variables (general life satisfaction, satisfaction with work, satisfaction with family life), control strategies (self-protection, disengagement) and life domains (work, family) one standalone model was setup, resulting in twelve models to be tested. We abstained from correcting for multiple testing because the predictor variables in the different models were substantially correlated so that the single models could not be considered independent evidence for the hypothesis anyway. The combination of different control strategies, life domains and outcome variables was rather meant to explore one and the same hypothesized association from slightly different perspectives.

Each model was set up by sequentially including intercept, variance components, and main effect predictors (control strategy, opportunity structures) in the first steps. In the last step, the interaction term between the control strategy and opportunity structures was entered into the equation in order to test the hypothesis. A sequential model comparison was performed which is described in full detail by Tomasik (2008) together with further information on model parameterization. The intra-class correlations were $\rho=.09$ for general life satisfaction, $\rho=.10$ for satisfaction with work, and $\rho=.05$ for satisfaction with family life. Coefficients of the models with a significant crosslevel interaction are presented in Table 4 for self-protection and in Table 5 for disengagement.

Results for self-protection (CSC I) in the work domain

For general life satisfaction, the cross-level interaction did not become significant ( $p=.10$ ) so that we had to abandon the hypothesis that the correlation between self-protection and general life satisfaction varies as a function of the

Table 4 Fixed effects coefficients $(\beta)$ for self-protection as control strategy

\begin{tabular}{|c|c|c|c|c|c|c|}
\hline \multirow[t]{3}{*}{ Life satisfaction } & \multicolumn{6}{|c|}{ Life domain } \\
\hline & \multicolumn{3}{|l|}{ Work } & \multicolumn{3}{|l|}{ Family } \\
\hline & General & Work & Family & General & Work & Family \\
\hline Intercept & & -.05 & -.02 & -.02 & -.05 & -.03 \\
\hline Control strategy & & -.02 & -.09 & -.04 & -.01 & $-.10^{*}$ \\
\hline Opportunity structures & & .02 & $-.15^{* *}$ & .03 & .06 & $-.09^{*}$ \\
\hline Cross-level interaction & n.s. & $-.09 * *$ & $-.09 *$ & $-.07 *$ & $-.09 * *$ & $-.12^{* *}$ \\
\hline
\end{tabular}

Note: Coefficients are printed only for models with a significant cross-level interaction between control strategy and opportunity structures

$* p<.05, * * p<.01$ 
Table 5 Fixed effects coefficients $(\beta)$ for disengagement as control strategy

\begin{tabular}{|c|c|c|c|c|c|c|}
\hline \multirow[t]{3}{*}{ Life satisfaction } & \multicolumn{6}{|c|}{ Life domain } \\
\hline & \multicolumn{3}{|l|}{ Work } & \multicolumn{3}{|l|}{ Family } \\
\hline & General & Work & Family & General & Work & Family \\
\hline Intercept & -.02 & & & -.02 & & \\
\hline Control strategy & -.07 & & & -.07 & & \\
\hline $\begin{array}{c}\text { Opportunity } \\
\text { structures }\end{array}$ & .03 & & & -.02 & & \\
\hline $\begin{array}{l}\text { Cross-level } \\
\text { interaction }\end{array}$ & $-.09 * *$ & n.s. & n.s. & $-.08 *$ & n.s. & n.s. \\
\hline
\end{tabular}

Note: Coefficients are printed only for models with a significant crosslevel interaction between control strategy and opportunity structures

$* p<.05, * * p<.01$

opportunity structure. Findings were different when satisfaction with work was analyzed as the response variable. There was a significant cross-level interaction between selfprotection and opportunity structure. As expected, there was a negative coefficient for the interaction term $(\beta=-.09$; $\mathrm{SE}=.04 ; p<.05)$ : Higher self-protection was correlated with higher satisfaction with work only under unfavorable opportunity structures and vice versa. This model is depicted in Fig. 1, a condition plot showing the relationship between two variables as a function of a third one. The conditional variable represents the opportunity structures and was split in three intervals that approximately comprised the same number of subjects. Under unfavorable conditions (left panel in Fig. 1) higher self-protection was associated with higher satisfaction. Individuals who employed more strategies of self-protection in the domain of work were thus more satisfied with it, if (and only if) the opportunity structures were unfavorable. Exactly the opposite was true for selfprotection under average (center panel in Fig. 1) and favorable opportunity structures (right panel in Fig. 1). This finding thus fully supported the hypothesis of this paper. Quite a similar picture emerged after the investigation of transfer effects between self-protection in the work domain and satisfaction with family life. There was a negative coefficient for the interaction term $(\beta=-.09$; $\mathrm{SE}=.05$; $p<.05)$ meaning that the correlation between self-protection and satisfaction with family was only positive under unfavorable conditions. When opportunity structures were not unfavorable, the correlation was negative. Summarizing the results for self-protection in the work domain, the hypothesized interactions were significant for the domainspecific measures of satisfaction with life but not for the general assessment of life satisfaction. There were thus both within-domain and between-domain effects.

\section{Results for self-protection (CSC I) in the family domain}

For family life, the first response variable to be investigated was satisfaction with life in general. The interaction coefficient was negative $(\beta=-.07 ; \mathrm{SE}=.04 ; p<.05)$ so that under unfavorable opportunity structures, the relationship between self-protection and general satisfaction with life
Fig. 1 Correlation of selfprotection at work and satisfaction with work conditional on work-related opportunity structures

\section{Condition: Opportunity Structures Work (z-score)}
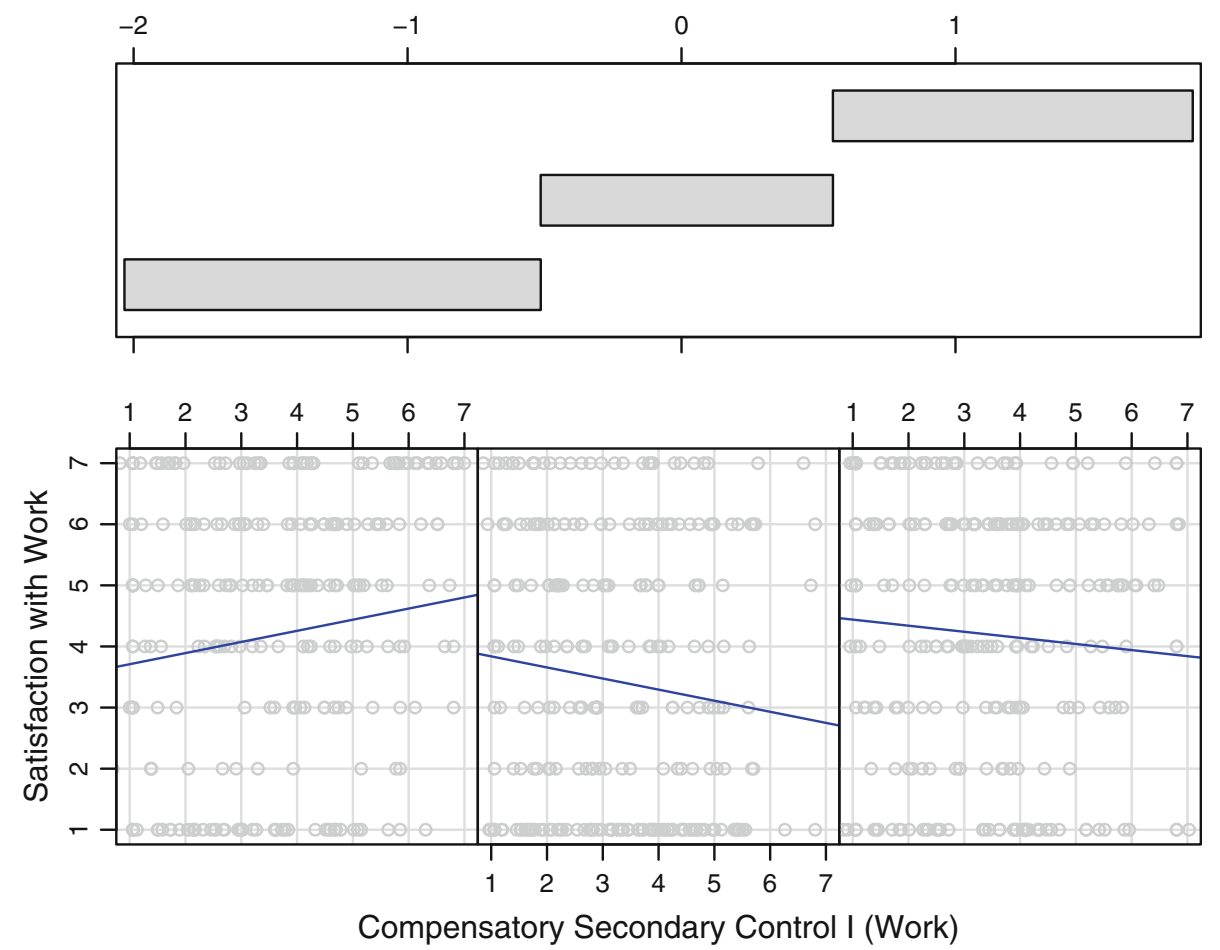
was substantially positive, whereas exactly the opposite was the case under average and favorable opportunities. The next analysis investigated satisfaction with work as the response variable. Note, that since family related demands, self-protection in the family domain and family related opportunity structures were the predictor variables, satisfaction with work was a cross-domain outcome which allowed the investigation of transfer effects. The interaction term was significantly negative $(\beta=-.09$; $\mathrm{SE}=.04$; $p<.05)$. Again, there was a positive relationship between self-protection and life satisfaction only under unfavorable opportunity structures. Turning to the effects of self-protection in family on satisfaction with family life, there were even stronger effects. The interaction effect was significant and, as compared to other predictor-outcome-combinations, also quite large $(\beta=-.12 ; \mathrm{SE}=.05 ; p<.05)$. Summarizing the findings for self-protection in the family domain, the hypothesis of this paper was fully supported. Under conditions unfavorable for families, individuals who endorsed self-protective strategies to a greater extent did also report higher satisfaction with life in general, higher satisfaction with their family life, and also higher satisfaction with work. The last effect can be interpreted as a transfer effect between family and work domains. As one would expect, the transfer effect was numerically not as large as the direct effect.

\section{Results for disengagement (CSC II) in the work domain}

For disengagement in the work domain, the crucial interaction term for general satisfaction with life was significantly negative $(\beta=-.09 ; \mathrm{SE}=.04 ; p<.05)$ meaning that under unfavorable opportunity structures, disengagement and satisfaction with life were positively correlated, whereas both under average and under favorable opportunity structures the correlation was negative. Another conclusion needs to be drawn when investigating satisfaction with work and satisfaction with family life as the response variables. In neither of these models the interaction term became significant. Hence, disengagement in the work domain did only interact significantly with work related opportunity structures when general life satisfaction was considered as the response variable. Disengagement under favorable and unfavorable conditions did only have a differential functionality when individuals considered an overall evaluation of their lives. In other words, there were neither direct nor transfer effects on domain-specific satisfaction.

Results for disengagement (CSC II) in the family domain

Finally, the correlation between disengagement from family related demands, family related opportunity structures and measures of life satisfaction was investigated. The three analyses yielded results comparable to those for disengagement in the work domain presented in the last paragraphs. For general life satisfaction, the crosslevel interaction term between disengagement and opportunities was significantly negative $(\beta=-.08 ; \mathrm{SE}=.04$; $p<.05)$. Investigating satisfaction with work and with family life as the response variables, no interaction term became significant. The conclusions that can be drawn for disengagement from family related demands correspond to those for disengagement in the work domain. The expected interaction became only significant when general life satisfaction was considered as the response variable. No interaction between disengagement and opportunity structures was present when domain-specific measures of life satisfaction were considered.

\section{Thresholds of developmental barriers}

Post-hoc analyses were performed to determine the critical level in local opportunity structures at which the beneficial effects of compensatory secondary control set in. A rough but very simple approach to determine this critical point is to calculate the value of opportunity structures for which the slope of the actual regression line between the control strategy and life satisfaction is zero. This estimation yielded different critical values for the different combinations between control strategy and response variable. With some tolerance for inaccuracy, the following approximations describe the results best: For self-protection, the critical threshold is located around $z \approx-.20$ when satisfaction with work is considered as the outcome variable and around $z \approx-.80$ for satisfaction with family life. For disengagement and general life satisfaction it is also around $z \approx-.80$ for both work and family life. In other words, with opportunity structures lower than one-fifth to fourfifth standard deviations below the mean, compensatory secondary control is, on the average, better for subjective well-being. In this data set, this roughly represented an Eastern German town with an unemployment rate of $19.50 \%$ and a proportion of long-term unemployed of $42.30 \%$ as compared to the overall average of $12.50 \%$ and $35.44 \%$, respectively.

\section{Discussion}

The starting point of this paper was the notion that social change confronts individuals with new demands that may overtax the reserve capacities of those individuals who live under conditions of very low controllability. The demands investigated here refer to the major societal trends outlined at the outset of this paper and comprised manifestations of 
structural uncertainty in the proximal developmental context of individuals, affecting the domains of work and family (Tomasik and Silbereisen 2009). Despite the potentially augmented role of individuals in negotiating their development in times of rapid social change, there are only few psychological studies directly addressing the interaction between developmental regulation by the individual and opportunities in the social ecology. In the current study, developmental regulation concerned the role of engagement or disengagement with goals, and the geographical variation in opportunity structures indicated the social ecology. Thereby we were able to test the adaptive value of goal disengagement by comparing individuals living in regions with different opportunities for mastering demands related to social change. In doing so, we made use of objective descriptions of relevant contextual opportunity structures. The conceptual link of these variables to demands of social change in terms of economic prosperity and family-friendliness made them highly relevant measures of opportunities. This procedure also had the advantage of protecting from spurious effects of shared method variance which may occur when all data is provided by the individual only (Feldman and Lynch 1988). The results thus offer additional and independent support for the underlying theory.

The hypothesis of this paper concerned individuals facing a developmental barrier for the mastery of demands related to social change. Under such conditions individuals were expected to report higher satisfaction with life if they exerted higher compensatory secondary control striving (i.e., selfprotection and disengagement) to master these demands. This hypothesis is not trivial, particularly when we consider compensatory secondary control related to normative developmental goals. These internalized goals constitute an important part of the individual self-definition and structure our daily activities and our interpretation of events. Furthermore, the pursuit of developmental goals is socially highly appreciated and disengagement from these goals not always a socially accepted alternative (note such proverbs as "winners never quit and quitters never win"). Thus, compensatory secondary control is likely to evoke negative emotions of self-blame, anger, and regret (Gilovich and Medvec 1995) which can be considered the psychological costs of this control strategy. Moreover, disengagement from normative goals and demands is prone to formal and informal social sanctions (Heckhausen 1999) which can be considered its social cost. The psychological and social costs taken together might very well exceed the theoretically expected benefits of self-protection and disengagement.

In terms of significant findings, a consistent pattern of two-way cross-level interactions between opportunity structures and control strategies emerged, allowing for basically three central conclusions. The first one concerns self-protective control strategies. As expected, these strategies were correlated with higher levels of domain-specific satisfaction with life when opportunity structures were unfavorable. Results for those individuals living under more favorable conditions, however, showed that selfprotective strategies did not improve their life satisfaction, but even decreased it. Self-protection under more favorable conditions was negatively related to domain-specific satisfaction. Not seizing the opportunities that favorable conditions offer but rather withdrawing into self-protective attributions is dysfunctional and consequently associated with lower satisfaction. Hence, demands can not always be dealt with by denying personal responsibility and hiding behind alleviative attributions. Interestingly, the thresholds at which self-protective strategies started having beneficial effects were different for work and family life. Whereas self-protective attributions were already effective at about average economic conditions on the regional level $(z \approx$ -.20 as compared to all regions investigated), the opportunities for families had to be really bad $(z \approx-.80)$ to make self-protection an effective means for higher subjective well-being. These figures may be interpreted in terms of higher psychological and social costs associated with self-protection in the family domain. Although one could argue that these costs are similar for the two domains of life, it is plausible to assume that the two life domains differ with respect to the justifiability of self-protective strategies against oneself and others. In the domain of work, one can blame colleagues, the boss, the company, the national economy, the economic system itself, globalization, international competition, and many more which are rather far away from the person, thus less verifiable and more easily to propone. This is not so easy in the more personal family domain simply because fewer individuals and institutions are involved and because there is often much more personal responsibility concerning familyrelated demands which makes self-protective attributions less justifiable.

The second conclusion that can be drawn from the results concerns direct effects of the demands within the same life domain and indirect effects of the demands from one domain of life to the other. Self-protection was-of course only under unfavorable conditions-positively correlated with domain-specific satisfaction both within the respective life domain and in the adjacent one. Individuals who used self-protective strategies to deal with unattainable demands at work reported higher satisfaction with work and their family life. The same is true for mastering demands in family life. There is also some evidence for positive effects on general life satisfaction as the outcome variable. Only self-protective control in the family domain was correlated with general life satisfaction. The indirect effects that systematically emerged demonstrate the importance of 
self-protective strategies under unfavorable conditions. One can conclude that exposure to unattainable demands of social change unprotected by compensatory secondary control bears the risk of severely influencing different life domains in a negative way. If not adequately dealt with, a high load of demands of social change thus has the potential to undermine individual adjustment and development in a substantial, broad, and thus non-ignorable way.

The third conclusion pertains to the findings for disengagement. Of the two aspects of compensatory secondary control strategies, disengagement is the more radical one. This cannot only be assumed theoretically but is also reflected in the relatively bad opportunities $(z \approx-80)$ that are necessary to turn disengagement an adaptive control strategy. The low threshold applied both to the domain of work and to the domain of family. As hypothesized, individuals who disengaged under unfavorable conditions were more satisfied with their life in general as compared to those who did not. Additionally, this relation between disengagement and general life satisfaction reversed under favorable conditions. This shows that it is not disengagement per se that is positively associated with satisfaction but disengagement in the right context. However, the hypothesis could only be confirmed with regard to general life satisfaction, not domain-specific satisfaction with work or family. Our findings concerning disengagement emphasize its importance for the overall satisfaction in life. If we consider general life satisfaction a broad indicator that an individual is on the right developmental track, these findings show that failure in one distinct domain does not need to harm overall functioning. However, one may ask why the more specific measures of satisfaction were not affected positively. Although it is not very sound to interpret non-significant findings we nevertheless want to suggest an answer to this question. Our line of thought starts with the assumption that the costs of disengagement in terms of formal and informal social sanctions or feelings of regret manifest themselves domain-specifically in the first instance. The effect is a reduced satisfaction with this domain due to a more negative evaluation of this domain. This then usually influences the overall evaluation of one's life unless the domain is not relevant for one's self. Failure to find a suitable job, for instance, reduces the satisfaction with work life and assumed that work is an important part of the self, general life satisfaction is also likely to drop. Disengagement now may disrupt this mechanism by reducing the relevance of a single life domain for the general evaluation of one's life. Whatever happens in this domain will less or even not at all affect general satisfaction with life so that all costs related to disengagement will affect domain-specific satisfaction only.

Taken together, the results presented in this paper support the theoretical considerations introduced by researchers who share a dual-process view on adaptive behavior (e.g., Brandtstädter 2010; Heckhausen et al. 2010; Wrosch et al. 2003). The crucial variable that defined whether or not compensatory secondary control is beneficial was the degree of deprivation/constraints for career and family-related goal striving present in the geographical region. We investigated such properties of the context that were directly related to the mastery of demands of social change so that the associations hypothesized were plausible to assume. By using the region as one level of analysis we operationalized the opportunities relevant for goal attainment rather distally from the person, at least as compared to previous studies dealing with the benefits of compensatory secondary control. These studies mainly investigated uncontrollability in narrowly described developmental settings such as the work place or the own transition from school to work; or they defined uncontrollability in terms of personal limitations or biological factors (for review, see Heckhausen et al. 2010). The social ecology, even if measured at the level we did, seems to be at least as important for developmental regulation as more proximal variables (e.g., subjectively assessed constraints to personal control). This again emphasizes the strong influence of the broader socio-economic context on individual adaptation and development.

One can think of two major mechanisms how compensatory secondary control affects subjective well-being under unfavorable contextual conditions: frustration and defeat associated with repeated failure and futile investment of precious action resources. First, low contextual opportunities are directly related to a lower probability for success of primary control striving. A high unemployment rate, for instance, makes a successful job search very difficult and individuals who in spite of the uncontrollability invest time and efforts in finding a job will most likely experience repeated failure which is likely to have negative psychological effects. There is evidence that repeated experiences of uncontrollability may result in ruminative coping (Nolen-Hoeksema et al. 1994), depressive symptomatology (Thompson et al. 1998) and "learned helplessness" (Abramson et al. 1978). Compensatory secondary control prevents repeated experiences of failure and thus its negative psychological consequences. Second, persistent engagement will consume costly resources such as time or self-efficacy beliefs that might otherwise have been invested more successfully into the optimization of other life domains (Baumeister and Scher 1988; Heckhausen 1999; Heckhausen et al. 2010). As a consequence, the failure to withdraw commitment from unattainable demands will restrain individuals to capitalize on success in other tasks and thus to maximize their primary control capacity over the life span. Compensatory secondary control releases resources necessary for primary control 
striving in other task or domains of life and opens up the mind for alternative options.

Elucidating the temporal sequence of the two mechanisms should be addressed by future research. It is plausible to assume that the prevention of failure is responsible for a short-term effect on subjective well-being and the release of resources functions in the long run when reengagement with more promising goals sets in. For this reason, Hofäcker et al. 2010 argue that it is the latter mechanism that is mainly responsible for the adaptive value of compensatory secondary control. Following this line of thinking, the distress-relieving function of compensatory secondary control may even turn maladaptive in the long run since it would permanently undermine primary control striving. This is what makes compensatory secondary control a delicate way of dealing with demands of social change which bears the risk of detrimental effects both at the level of the individual and the level of society. If used just as a means to inoculate oneself against social change, compensatory secondary control has the potential to block primary control striving of individuals. Consequently, this could hinder the advancement of those regions which are in particular need for economic, civic, and political engagement of their inhabitants. From this perspective, it seems like a social paradox that regions with high developmental barriers at the same time seem to promote compensatory secondary control (Pinquart et al. 2009). Individuals who live in regions with unfavorable opportunity structures can compare themselves with many others who have failed in primary control striving which makes own compensatory secondary control more justifiable and own failure psychologically less severe. Devastated regions also offer more "self-evident reasons" for self-protection and disengagement and it is indeed more reasonable to blame the economy for the lacking of employment opportunities in regions with high unemployment as compared to regions where unemployment is low. Thus, when opportunities are unfavorable, compensatory secondary control is perfectly justifiable against oneself and others and less likely to be considered a "lame excuse" for personal failure. Social policy needs to be aware of this paradox when trying to increase common welfare in disadvantaged regions undergoing rapid social change.

\section{Limitations}

The study certainly has some limitations of which its correlative nature is probably the most severe one. The individual level variables were assessed simultaneously which does not allow a conclusion of the causal direction of the effects. Consequently, the context dependent associations between compensatory secondary control and subjective well-being could also be interpreted in the other way around: Individuals might exert different control strategies as a function of their satisfaction with life which would shed a different light on the results. Although the final proof for our interpretation requires experimental or at least prospective longitudinal research, there are some good reasons why the causal direction suggested here can be considered more likely than the other way around. To begin with, there are longitudinal studies indicating that the effect from control strategies to well-being is the predominant one (e.g., Rothermund and Brandtstädter 2003). Furthermore, the wording of the demands assessed suggests a temporal sequence. The items to which the control strategies refer entailed a reference to the situation 5 years ago, thus representing a subjectively experienced change as compared to the past, rooted in the challenges of social change addressed (Tomasik and Silbereisen 2009). Subjective well-being, however, was assessed explicitly referring to the present life situation.

Another possible limitation is that many of the regions with an unfavorable opportunity structure were actually located in Eastern Germany, whereas favorable opportunities were more likely to be found in the West. This is a true reflection of the postunification situation in Germany (cf. Institut der deutschen Wirtschaft 2007). As region and opportunity were thus partly confounded, social and cultural differences between the population in the two parts of Germany may be responsible for the positive association between compensatory secondary control and economically challenged regions. However, post-hoc analyses revealed that the cross-level interactions were still significant and in the hypothesized direction when data were analyzed separately for each part of the country. Consequently, we consider the reported findings not rooted in social and cultural differences between West and East.

\section{Conclusion}

The results suggest that favorable opportunities do not by themselves bring about positive subjective well-being and developmental barriers do not necessarily lead to despair. The vast potential of human self-regulation renders possible a life of contentment and happiness despite an objectively unfavorable situation. Our findings show that those who lived under unfavorable conditions and who at the same time managed to disengage from the unattainable demands, or at least protected their motivational and emotional potential, were among the subjects reporting the highest satisfaction with life. Thus, developmental regulation taking into account opportunities and constraints in the social ecology plays an important role for individual adaptation and development. One can even argue that 
strategies of self-protection and disengagement might today be even more important than ever and knowing when to "hang on" and when to "let go" (Miller and Wrosch, 2007; Pyszczynski and Greenberg 1992) can turn out an important asset in times of rapid social change.

Acknowledgments The Jena Study on Social Change and Human Development is part of the research project "Individual and Social Resources for Coping with Social Change: Development and Psychosocial Effects" (Principal Investigator: Prof. Dr. Rainer K. Silbereisen) and was funded by the German Research Foundation (DFG) as a subproject (SFB580-04-C6) of the Collaborative Research Center 580 "Social Developments in Post-Socialistic Societies: Discontinuity, Tradition, Structural Formation". This paper summarizes a significant part of the unpublished dissertation thesis of the first author titled "Developmental Barriers and the Benefits of Disengagement". An earlier version of this manuscript was presented at an international expert workshop "Social Change: Concepts and Results" in Würzburg, Germany. The preparation of this manuscript was supported by a PATHWAYS fellowship (see http://www.pathwaystoadulthood.org) from the Jacobs Foundation. We thank all individuals who kindly volunteered to participate this study.

Open Access This article is distributed under the terms of the Creative Commons Attribution Noncommercial License which permits any noncommercial use, distribution, and reproduction in any medium, provided the original author(s) and source are credited.

\section{References}

Abramson, L. Y., Seligman, M. E. P., \& Teasdale, J. D. (1978). Learned helplessness in humans: Critique and reformulation. Journal of Abnormal Psychology, 87, 49-74.

Baumeister, R. F., \& Scher, S. J. (1988). Self-defeating behavior patterns among normal individuals: Review and analysis of common self-destructive tendencies. Psychological Bulletin, 104, 3-22.

Brandtstädter, J. (2010). Life management in developmental settings of modernity: Challenges to the adaptive self. In R. K. Silbereisen \& X. Chen (Eds.), Social change and human development: Concept and results (pp. 50-72). London: Sage Publications.

Brandtstädter, J., \& Renner, G. (1992). Coping with discrepancies between aspirations and achievements in adult development: A dual-process model. In L. Montada, S.-H. Filipp, \& M. J. Lerner (Eds.), Life crises and experiences of loss in adulthood (pp. 301-319). Hillsdale, NJ: Lawrence Erlbaum Associates.

Brandtstädter, J., \& Rothermund, K. (2002). The life-course dynamics of goal pursuit and goal adjustment: A two-process framework. Developmental Review, 22, 117-150.

Brückner, H., \& Mayer, K. U. (2005). The de-standardization of the life course: What it might mean and if it means anything whether it actually took place. Advances in Life Course Research, 9, 27-54.

Bucksteeg, M., Kaiser, P., \& Lehmann, K. (2006). Potenziale erschließen-Familienatlas 2005 [Developing potentials-The family atlas 2005]. Berlin, Germany: Bundesministerium für Familie, Senioren, Frauen und Jugend.

Bynner, J. (2001). British youth transitions in comparative perspective. Journal of Youth Studies, 4, 5-23.
Campbell, A., Converse, P. E., \& Rodgers, W. L. (1976). The quality of American life: Perceptions, evaluations, and satisfaction. New York: McGraw-Hill.

Carver, C. S., \& Scheier, M. F. (1998). On the self-regulation of behavior. New York: Cambridge University Press.

Diener, E. (1984). Subjective well-being. Psychological Bulletin, 95, $542-575$.

Elliott, A., \& Lemert, C. (2006). The new individualism: The emotional costs of globalization. London: Routledge.

Feldman, J. M., \& Lynch, J. G. (1988). Self-generated validity and other effects of measurement on belief, attitude, intention, and behavior. Journal of Applied Psychology, 73, 421-435.

Gilovich, T., \& Medvec, V. H. (1995). The experience of regret: What, when, and why. Psychological Review, 102, 379-395.

Hank, K. (2002). Regional social contexts and individual fertility decisions: A multilevel analyses of first and second order births in Western Germany. European Journal of Population, 18, 281-299.

Heckhausen, J. (1999). Developmental regulation in adulthood: Agenormative and sociostructural constraints as adaptive challenges. New York: Cambridge University Press.

Heckhausen, J., \& Schulz, R. (1993). Optimization by selection and compensation: Balancing primary and secondary control in lifespan development. International Journal of Behavior Development, 16, 287-303.

Heckhausen, J., \& Schulz, R. (1995). A life-span theory of control. Psychological Review, 102, 284-304.

Heckhausen, J., \& Schulz, R. (1999). The primacy of primary control is a human universal: A reply to Gould's (1999) critique of the life-span theory of control. Psychological Review, 106, 605-609.

Heckhausen, J., Wrosch, C., \& Fleeson, W. (2001). Developmental regulation before and after a developmental deadline: The sample case of 'biological clock' for childbearing. Psychology and Aging, 16, 400-413.

Heckhausen, J., Wrosch, C., \& Schulz, R. (2010). A motivational theory of life-span development. Psychological Review, 117, $32-60$.

Hofäcker, D., Buchholz, S., \& Blossfeld, H.-P. (2010). Globalisation, institutional filters and changing life course patterns in modern societies. A summary of the results from the GLOBALIFEproject. In R. K. Silbereisen \& X. Chen (Eds.), Social change and human development: Concept and results (pp. 101-124). London: Sage Publications.

Institut der deutschen Wirtschaft. (2007). Regionalranking 2006: Untersuchung von 435 Kreisen und kreisfreien Städten [Regional ranking 2006: Investigation of 435 counties and non-county municipalities]. Köln, Germany: Institut der deutschen Wirtschaft.

King, L. A., Scollon, C. K., Ramsey, C., \& Williams, T. (2000). Stories of life transition: Subjective well-being and ego development in parents of children with down syndrome. Journal of Research in Personality, 34, 509-536.

Larson, J. H., Wilson, S. M., \& Beley, R. (1994). The impact of job insecurity on marital and family relationships. Family Relations, 43, 138-143.

Mattlin, J. A., Wethington, E., \& Kessler, R. C. (1990). Situational determinants of coping and coping effectiveness. Journal of Health and Social Behavior, 31, 103-122.

McClelland, G. H., \& Judd, C. M. (1993). Statistical difficulties in detecting interactiuons and moderator effects. Psychological Bulletin, 114, 376-390.

Miller, G. E., \& Wrosch, C. (2007). You've gotta know when to fold'em: Goal disengagement and systemic inflammation in adolescence. Psychological Sciences, 18, 773-777. 
Moskowitz, J. T., Folkman, S., Collette, L., \& Vittinghoff, E. (1996). Coping and mood during AIDS-related caregiving and bereavement. Annals of Behavioral Medicine, 18, 49-57.

Nolen-Hoeksema, S., Parker, L. E., \& Larson, J. (1994). Ruminative coping with depressed mood following loss. Journal of Personality and Social Psychology, 67, 92-104.

Pinheiro, J. C., Bates, D. M., DebRoy, S., \& Sarkar, D. (2006). NLME: Linear and nonlinear mixed effects models [computer software and manual]. Retrieved from http://www.cran.rproject.org/.

Pinquart, M., \& Silbereisen, R. K. (2004). Human development in times of social change: Theoretical considerations and research needs. International Journal of Behavioral Development, 28, 289-298.

Pinquart, M., Silbereisen, R. K., \& Körner, A. (2009). Perceived work-related demands associated with social change, control strategies, and psychological well-being: Do associations between perceived social change, coping, and psychological well-being vary by regional economic conditions? Evidence from Germany. European Psychologist, 14, 207-219.

Pohl, S., Steyer, R., \& Kraus, K. (2008). Modeling method effects as individual causal effects. Journal of the Royal Statistical Society: Series A, 171, 41-63.

Poulin, M., Haase, C. M., \& Heckhausen, J. (2005). Engagement and disenagement across the life span: An analysis of two-process models of developmental regulation. In W. Greve, K. Rothermund, \& D. Wentura (Eds.), The adaptive self: Personal continuity and intentional self-development. Ashland, $\mathrm{OH}$ : Hogrefe \& Huber Publishers.

Pyszczynski, T., \& Greenberg, J. (1992). Hanging on and letting go: Understanding the onset, progression, and remission of depression. New York: Springer.

$\mathrm{R}$ Development Core Team. (2006). R: A language and environment for statistical computing. Vienna, Austria: R Foundation for Statistical Computing.

Reitzle, M., \& Silbereisen, R. K. (2000). The timing of adolescents' school-to-work transition in the course of social change: The example of German unification. Swiss Journal of Psychology, $59,240-255$.

Rothermund, K., \& Brandtstädter, J. (2003). Coping with deficits and losses in later life: From compensatory action to accommodation. Psychology and Aging, 18, 896-905.

Sameroff, A. J. (2000). Developmental systems and psychopathology. Development and Psychopathology, 12, 297-312.

Schoon, I. (2007). Adaptations to changing times: Agency in context. International Journal of Psychology, 42, 94-101.

Schulz, R., \& Heckhausen, J. (1999). Aging, culture and control: Setting a new research agenda. Journal of Gerontology: Psychological Sciences, 54B, P139-P145.

Shanahan, M., Elder, G. H., Jr., \& Miech, R. A. (1997). History and agency in men's lives: Pathways to achievement in cohort perspective. Sociology of Education, 70, 54-67.
Silbereisen, R. K., \& Wiesner, M. (2000). Cohort change in adolescent developmental timetables: Trends and possible reasons. In J. Heckhausen (Ed.), Motivational psychology of human development: Developing motivation and motivating development (pp. 271-284). Amsterdam: North-Holland.

Silva, J. A., \& Leichenko, R. M. (2004). Regional income inequality and international trade. Economic Geography, 80, 261-286.

Stallings, M. C., Dunham, C. C., Gatz, M., Baker, L. A., \& Bengtson, V. A. (1997). Relationships among life events and psychological well-being: More evidence for a two-factor theory of well-being. Journal of Applied Gerontology, 16, 104-119.

Tesch-Römer, C., Motel-Klingebiel, A., \& Tomasik, M. J. (2008). Gender differences in subjective well-being: Comparing societies with respect to gender equality. Social Indicators Research, 85, 329-349.

Thompson, T., Davis, H., \& Davidson, J. (1998). Attributional and affective responses of impostors to academic success and failure outcomes. Personality and Individual Differences, 25, 381-396.

Titma, M., \& Trapido, D. (2002). Prediction of success in postcommunist societies: Evidence from Latvia and Estonia. Society and Economy, 24, 297-331.

Titma, M., \& Tuma, N. B. (2005). Human agency in the transition from communism: Perspectives on the life course and aging. In K. Schaie \& G. H. Elder Jr (Eds.), Historical influences on lives and aging (pp. 108-143). New York: Springer.

Tomasik, M. J. (2008). Developmental barriers and the benefits of disengagement. Unpublished dissertation thesis, Friedrich Schiller University, Jena, Germany.

Tomasik, M. J., \& Silbereisen, R. K. (2009). Demands of social change as a function of the political context, institutional filters, and psychosocial resources. Social Indicators Research, 94, $13-28$.

Tunali, B., \& Power, T. G. (1993). Creating satisfaction: A psychological perspective on stress and coping in families of handicapped children. Journal of Child Psychology and Psychiatry and Allied Disciplines, 34, 945-957.

von der Heyde, C., \& Loeffler, U. (1993). Die ADM-Stichprobe [The ADM sample]. Planung und Analyse, 20, 49-53.

Williamson, G. M., \& Schulz, R. (1993). Coping with specific stressors in Alzheimers's disease caregiving. The Gerontologist, $33,747-755$.

Wrosch, C., \& Heckhausen, J. (1999). Control processes before and after passing a developmental deadline: Activation and deactivation of intimate relationship goals. Journal of Personality and Social Psychology, 77, 415-427.

Wrosch, C., Scheier, M. F., Carver, C. S., \& Schulz, R. (2003a). The importance of goal disengagement in adaptive self-regulation: When giving up is beneficial. Self and Identity, 2, 1-20.

Wrosch, C., Scheier, M. F., Miller, G. E., Schulz, R., \& Carver, C. S. (2003b). Adaptive self-regulation of unattainable goals: Goal disengagement, goal reengagement, and subjective well-being. Personality and Social Psychology Bulletin, 29, 1494-1508. 